\title{
POTENTIAL OF LEGOC EV3 MOBILE ROBOTS
}

\author{
Liberios VOKOROKOS, Juraj MIHAL'OV, Eva CHOVANCOVÁ \\ Department of Computers and Informatics, Faculty of Electrical Engineering and Informatics, Technical University of Košice, \\ Letná 9, 04200 Košice, tel. 055/602 2676, E-mail: \{liberios.vokorokos, juraj.mihalov, eva.chovancova\}@ tuke.sk
}

\begin{abstract}
This paper highlights the potential of LEGO@ EV3 mobile robots in industry, especially as an alternative to life-threatening professions. In the context of experimental construction of a powerful robot, particular sections carefully describe the story of a successful project called Snail (the robot), its mission and technical details. The most important scientific contribution is believed to be the design of powerful robot solution as an experimental proof that LEGO@C based low-cost commercial robotic platform might be an interesting choice when dealing with difficult situations, money and knowledge. The robot is adapted to moving up the ladder including $L E G O @$ Cit equipped by various sensors for data measuring as well as orientation in the terrain.
\end{abstract}

Keywords: Snail, LEGO@ EV3, Mindstorms, LabVIEW, mobile robot, pollution measurement

\section{INTRODUCTION}

Potential of LEGOC based low-cost commercial robotic platform has been discussed in several studies, drawing attention to many areas. For example, E. Cuevas et al. [1] focused on learning, studying capabilities and limitations of mobile robots within two projects: First one focused on construction of a robotic vehicle able to follow predefined paths, second one dealing with problem of position control. Within the following study, our intention is similar: To provide a flexible low-cost IT solution helpful for a human. However, while authors of [1] introduced robot based on LEGOC NXT system, our solution called Snail benefits from EV3-based system (more in Sec. 2).

Our main hypothesis is: Low-cost mobile robots may be a flexible alternative to human-threatening professions which is inexpensively reconfigurable to different purposes. In order to prove the hypothesis, we experimentally constructed Snail, a mobile robot. In general, Snail is a flexible low-cost robotic solution accustomed to movement up the ladder and measurement of various data, e.g. radiation or pollution, depending on human needs. That is, the robot is capable of human replacement in dangerous environments. As already mentioned, the solution benefits mainly from LEGOC as well as from LabVIEW and Mindstorms. The robot was constructed by students (not professionals) and as an added value, it was successful in several contests.

More similar projects have been introduced, however, only a few in the area of life-threatening professions. For example, S. Moor et al. developed inexpensive and flexible process control kits including both hardware and software [2], where each kit requires approx. \$ 1200 in parts and is able to carry out a range of level, flow and temperature control experiments. Another solution introduced a framework for rapid remote experiment implementation [3], based on in-house development embedded control hardware and two commercially available software packages: MATLAB/Simulink and LabVIEW. They argue that the combination of hardware and software solution enabled the rapid and easy creation of different interactive remote control experiments while in the friendly user interface, the remote user could change predefined system parameters and observe the system response in textual, graphical, or video format. Similar motivation as ours was published in [4] as a competition based product built on LEGOC NXT Mindstorms kits and standard LabVIEW, however, avoiding solutions in life-threatening areas.

Currently, different languages and compilers for the LEGOC platform are available, providing multiple options to overcome commonly-found constraints while developing innovative IT solutions under a friendly and easy to execute code. Authors of $[5]$ argue that in control engineering, realtime systems require floating point operations, extended sets of mathematical functions and clear debugging tools. This is why they decided to include ROBOTC (C) compiler in their solution. However, authors of [1] show some important compiling problems to be solved through a neat and comprehensive use of debugging tools and useful programming concepts.

This is why we focused on LabVIEW Mindstorms in the early stages of Snail development, similarly to [4], while authors of [3] preferred MATLAB/Simulink within the development of rapid experiment control algorithm, in combination with LabVIEW towards the user front-end and remote control. LabVIEW is a programming environment offering support for data acquisition hardware, built-in libraries, multitasking, and simple definition of user interfaces and is widely used in professional engineering [6] [7].

In the following sections we intruduce the Snail robot, background of the experiment and its constructional details (Sec. 2) and conclusions regarding the hypothesis and the potential of mobile robots (Sec. 3).

\section{EXPERIMENT}

Regarding the hypothesis, our experiment pursued the following interests:

- To find an IT solution which can replace human in life-threatening professions,

- To construct a mobile robot undemanding on neither hardware nor software part,

- To provide an inexpensive product which can be easily reconfigurable and reconstructable according to human needs. 


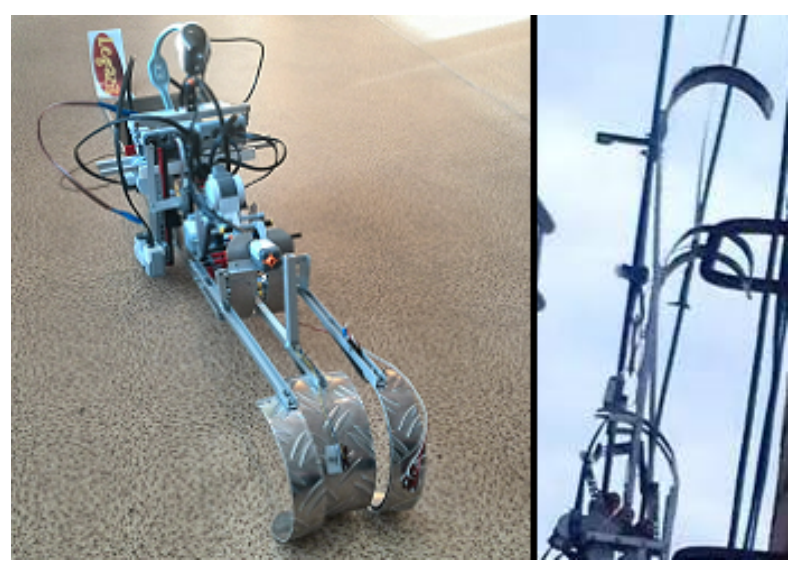

Fig. 1 Snail: The main construction

As a result, we turned to high-school students to participate in the experiment. The main assumption was that if inexperienced students are able to construct a robot and accustom it to specific conditions, then such a solution might be low-cost for the industry and flexible for the users. From the student point of view, the main motivations included a desire to create something real and useful, a possibility to show off, and to be successful in a contes 1

\subsection{Front-end}

Skeleton of the Snail robot is constructed from alloy of copper, magnesium and aluminum, known as Duralumin (durable aluminum, Al-Cu4-Mg). As stated in [8], this material guarantees light and strong structure.

The entire skeleton consists of several profiles, so it ensures the strength as well as an easy access to particular components. This way, the construction is always open for any refines or enhancements. The lower part is composed of two skis (arms) on both sides, ended by radius profiles (see Fig. 1). In order to ensure the friction is minimized, this supporting part had to be blotted until smooth (literature background in [9] [10]).

The center of gravity contains so-called cube cage, to which the entire control system is attached. The power supply is attached as well, consisting of an accummulator with the capacity of $5200 \mathrm{mAh}$, with the voltage of $7.4 \mathrm{~V}$. On top of the cage there are two control LEGO(C) EV3 units communicating through a daisy chain (USB 2.0) [11]. This way, it is possible to connect up to $4 \mathrm{EV} 3$ bricks of 4 ports in both upper and lower sides. The ports of the upper side of the brick are designed for the motors and the ports of the lower side are designed for the sensors.

On the right side, there is an 8-port multiplexer for the motors, connected to EV3 as a sensor. In addition to 4 LEGOC motors, the multiplexer is used for connection of another 8 servo motors. In comparison with LEGOC motors, which are connected to the source directly in the LEGO(c) brick, the 5200mAh accummulator is used as a power supply for all the servo motors of the robot (other manufacturer).

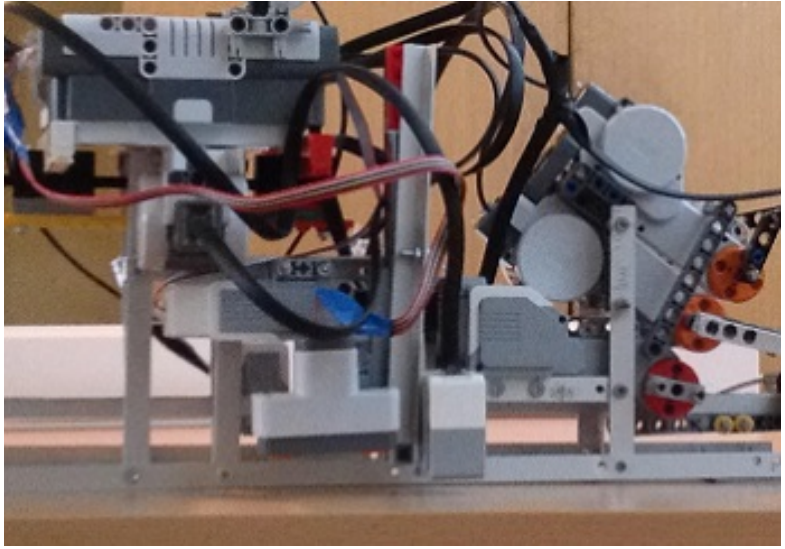

Fig. 2 Snail: Detailed view from the side

Vertical movement of the robot is ensured by a middle arm which is equipped by a toothed rail, one color sensor and two touch sensors. The arm is fastened, so it is hold by a servo motor which extends or retracts the arm. The arm is swiveled in or out within a specific moment determined by the color sensor. The sensor is positioned, so it is able to react on colored stripes on the construction. While moving up, the color sensor tracks the blue color and if noticed, the arm is swiveled out. While moving down, the color sensor tracks the red color and if noticed, the arm is swiveled in. This way, the robot can be controlled over the required step length at any time. More detailed view from the side is depicted in Fig. 2 .

\subsection{Back-end}

Ensuring the robot operation, the control system is located in EV3 bricks. The bricks were divided in two threads: the main and the subsidiary. The main application is implemented in Mindstorms as a sub-part of LabVIEW, making the programming graphical (see Fig. 3), however, the software environment is less difficult for unexperienced users. The entire application structure consists of various functions, blocks and loops, enclosing the blocks and functions to one circuit and creating specific steps. If the blocks are enclosed in loops and they are able to be used as separate steps in more parts, then it is possible to create separate blocks as one unit, save them and use when preforming other steps.

Every arm and every movement has its own line in the application, in which particular functions are determined. The blocks are labeled by number 1 to 3 and they indicate to which arm is the block information dedicated. In the upper part of every block, there are numbers 1 or 2 indicating, with which control unit is the command associated. Another box specifies ports of the control unit.

Commands associated with the robot movement are provided by the main thread, which is from the computer point of view considered to be the main control unit. On the contrary, the subsidiary thread consists of commands intended for data acquisition through particular measuring components. This part is subordinated to the main EV3 brick.

${ }^{1}$ Two students Igor Žovtík and Michal Urban participated in the experiment as main constructors, being successful in Na Komin 2014 and the Festival of Science 2014 in Slovakia, and in the I-Sweeep 2015 in Houston, USA 


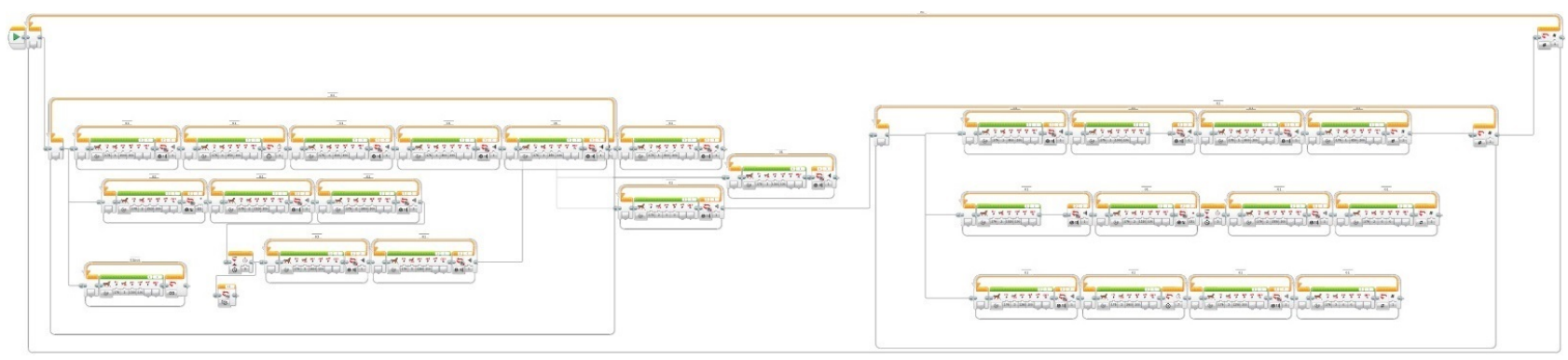

Fig. 3 Snail: Graphical representation of the application in EV3 Mindstorms

Except for the servo motors, every sensor and motor communication is binary. Between sensors of the main unit there is an adapter with 8 inputs and 1 output for EV3 as a signal convertor - demultiplexer ${ }^{2}$

Table 1 NXT vs EV3: Comparison

\begin{tabular}{|l|c|c|}
\hline Processor & NXT & EV3 \\
RAM & Atmel 32-bit ARM & ARM9 \\
Flash & $64 \mathrm{kB}$ & $64 \mathrm{MB}$ \\
OS & $256 \mathrm{kB}$ & $16 \mathrm{MB}$ \\
SD card & Proprietary & Linux-based \\
Smart devcs & n/a & Micro SD 32 GB \\
WiFi & Android & Android/Apple \\
Bluetooth & Yes & Yes \\
Display & $100 \times 64$ & Yes \\
Sensor ports & 4 & $178 \times 128$ \\
Motor ports & 3 & 4 \\
USB ports & USB 2.0 & USB mini \\
\hline
\end{tabular}
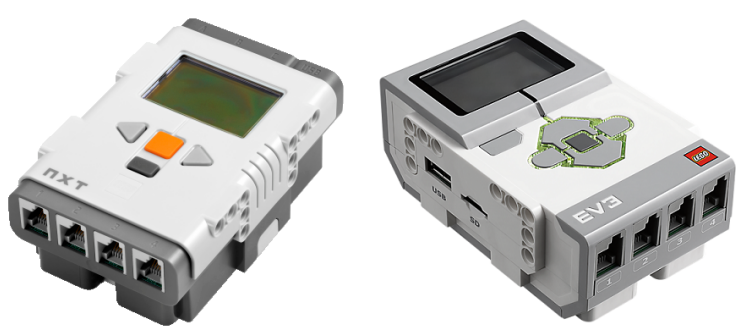

Fig. 4 NXT vs EV3 [15]
As already mentioned, the final robot construction is based on EV3 bricks. Even though some known robots are built on NXT (e.g. in [4] [13] [14]), after some investigation, our choice was EV3. Tab. 1 represents a simple comparison (pros and cons) of both alternatives.

\section{CONCLUSION}

We constructed a low-cost robot which is capable of climbing up the ladder (e.g. up the chimney) using a color and touch sensor. Throughout its mission, the robot is able to measure various data through particular sensors. In our experiment, we focused on pollution which, however, was not the main goal in our experiment. More significant fact is that the robot is able to move in highs as an alternative to life-threatening professions. Moreover, the robot is flexible enough, so it can measure data required by the user. The only condition is that particular sensors have to be attached to the robot.

Since the robot uses bricks attached to each other, another benefit is the possibility to transform the robot to another one. Overall, the EV3 bricks provide a flexible base for adding a hands-on component to the main thread. These bricks can easily be reproduced in another setting. Furthermore, EV3 units directly support LabVIEW. This way, it is possible to run standard LabVIEW programs remotely and also upload them to the EV3 bricks [4].

Another important fact is that the robot was not constructed through expensive or complex technologies. On the contrary, using LEGO(C) bricks we were able to construct the robot with high-school students. However, the Duralumin skeleton is unique, since it is accustomed to a specific movement (climbing up the ladder).

It this paper, we proved that we can consider lowcost mobile robots to be a flexible alternative to humanthreatening professions, creating other alternatives through the possibility of the robot reconfiguration. Within the further research we plan to focus on more complex solutions towards automated environment control through reconfigurable bricks interconnected to various sensors.

\footnotetext{
${ }^{2}$ Although its communication is hexadecimal, through the I2C protocol [12] it is able to send information to Mindstorms, where the additional block converts the signal.
} 


\section{ACKNOWLEDGEMENT}

This work was supported by the Slovak Research and Development Agency under the contract No. APVV-000810. We would also like to thank I. Žovtík and M. Urban, students actively involved in the Snail robot experiment.

\section{REFERENCES}

[1] CUEVAS, E. - ZALDIVAR, D. - PÉREZCISNEROS, M.: Low-cost commercial LEGOC platform for mobile robotics, Journal of Electrical Engineering Education 47, No. 2 (2010) 132-150

[2] MOOR, S. - PIERGIOVANNI, P. - METZGER, M: Process control kits: A hardware and software resource, 2005, IEEE Frontiers in education, pp. T2G27

[3] HERCOG, D. - GERGIČ, B. - URAN, S. - JEZERNIK, K.: A DSP-based remote control laboratory, IEEE Transactions on industrial electronics 54, No. 6 (2007) 3057-3068

[4] GÓMEZ DE GABRIEL, J. - MANDOW, A. e FERNÁNDEZ-LOZANO, J. - GARCÍA-CEREZO, A.: Using LEGO NXT mobile robots with LabVIEW for undergraduate courses on mechatronics, IEEE Transactions on education 54, No. 1 (2011) 41-57

[5] CANUDAS DE WIT, B. - SICILIANO, B. BASTIN, G.: Theory of robot control, 1997, Springer Science \& Business Media

[6] NITU, C. - GRAMESCU, B. - POMEAGA, C. TRUFASU, A.: Optomechatronic system for position detection of a mobile mini-robot, IEEE Transactions on industrial electronics 52, No. 4 (2005) 969-973

[7] GARCÍA-CEREZO, A. - MANDOW, A. MARTÍNEZ, L. - GÓMEZ DE GABRIEL, J. MORALES, J. - CRUZ, A. - REINA, A. SERÓN, J.: Development of ALACRANE: A mobile robotic assistance for exploration and rescue missions, 2007, IEEE SSRR2007, pp. 1-6

[8] PANDEY, A. - DUBEY, A.: Taguchi based fuzzy logic optimization of multiple quality characteristics in laser cutting of Duralumin sheet, Optics and lasers in engineering 50, No. 3 (2012) 328-335

[9] CANUDAS DE WIT, B.: A survey of models, analysis tools and compensation methods for the control of machines with friction, Automaica 30, No. 7 (1994) 1083-1138

[10] CAI, Y. - YANG, S.: A Survey on multi-robot systems, 2012, IEEE World Automation Congress (WAC), pp. 1-6

[11] ROBERTAZZI, T.: Processor equivalence for daisy chain load sharing processors, IEEE Transactions on aerospace and electronic systems 29, No. 4 (1999) 1216-1221

[12] OBERG, J. - HU, W. - IRTURK, A. - TIWARI, M. - SHERWOOD, T. - KASTNER, R.: Informa- tion flow isolation in I2C and USB, 2011, ACM/IEEE Design automation conference, pp. 254-259

[13] MARZAT, J. — PIET-LAHANIER, H. - KAHN, A.: Cooperative guidance of Lego Mindstorms NXT mobile robots, 2014, IEEE Informatics in control, automation and robotics (ICINCO), pp. 605-610

[14] BAPTISTA, L. - BÓIA, N. - MARTINS, J. — SÁ DA COSTA, J.: Interaction control experiments for a robot with one flexible link, Informatics in control automation and robotics 15, No. 1 (2008) 155-168

[15] LEGO(C) Mindstorms Gallery [cited: 03.03.2015] http://www.lego.com/en-us/mindstorms/ gallery

Received June 30, 2015, accepted August 13, 2015

\section{BIOGRAPHIES}

Liberios Vokorokos was born in 1966 in Greece and he is Full Professor of Computer Science and Informatics at the Department of Computers and Informatics, Technical University of Košice, Slovakia. He received his MSc. with honours in Computer Science in 1991 and his PhD. in Computer Science in 2000 from Technical University of Košice. In 2005 he was appointed as Full Professor in Computer Science and Informatics. Since 1995 he has worked for the Department of Computers and Informatics, Technical University of Košice and currently he holds the position of Dean at the Faculty of Electrical Engineering and Informatics. He is author of several monographs in the area of parallel computers and Data Flow type. Currently his research area covers diagnostics of complex systems as well as anomaly-based intrusion detection systems. His other professional interests include the membership in the Advisory Committee of Informatization at the faculty and Advisory Board of the Development and Informatization at Technical University of Košice.

Juraj Mihal'ov is PhD student at the Department of Computers and Informatics, Faculty of Electrical Engineering and Informatics, Technical University of Košice, Slovakia. He received his MSc. in Process Control and Automation in 2011 from Technical University of Košice. In 2011-2015 he worked as Network and Hardware Instructor at Secondary Technical Automotive School and received several awards in robot construction. The subject of his research is Environment Analysis and Control through Sensors.

Eva Chovancová was born in 1985 in Slovakia and she is Professor Assistant at the Department of Computers and Informatics, Faculty of Electrical Engineering and Informatics, Technical University of Košice, Slovakia. She received her MSc. in Computer Science in 2009 and her PhD. in Informatics in 2012 from Technical University of Košice. In 2010 she spent 1 month at the Department of Telematics at Norwegian University of Science and Technology in Trondheim, Norway. The subject of her research is multicore architectures and accelaration of computer vision computations. 